\title{
The Mechanism of Erythrocytes Aggregation in EDTA-Blood of Ovarian Cancer Patients Viewed by Coulomb's Law
}

\author{
Kuncoro Asih Nugroho ${ }^{\#, *}$, Kamsul Abraha ${ }^{\#}$, Ngadikun ${ }^{+}$

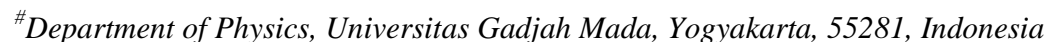 \\ E-mail:kuncoronugroho@yahoo.com,kamsul@ugm.ac.id \\ *Department of physics Education, Universitas Negeri Yogyakarta, 55281, Indonesia \\ ${ }^{+}$Department of Biochemistry, Universitas Gadjah Mada, Yogyakarta, 55281, Indonesia \\ E-mail:ngadikunugm@yahoo.co.id
}

\begin{abstract}
The objective of this research is to assess the application of Coulomb's law in complex systems. The observed erythrocyte interaction is erythrocytes in the EDTA-blood. The detection of the erythrocyte interaction uses a spectrophotometer with $\lambda=560 \mathrm{~nm}$. The EDTA-blood in the cuvette is irradiated on the lower surface of the EDTA-blood. Data were analyzed using deterministic and stochastic approaches. Based on the data analysis, three deterministic and three stochastic parameters are obtained. The differences in the values of both deterministic and stochastic parameters of ovarian cancer and normal subject patients were analyzed using Mann-Whitney for non-normally distributed data, while normally distributed data were analyzed using t-test. The results of this calculation show that the parameters in both groups are not significantly different. The mechanism of absorbance pattern in terms of Coulomb's law cannot distinguish the patterns of erythrocyte interactions as living cells with the complexity of EDTA-blood composition in both normal and ovarian cancer subjects.
\end{abstract}

Keywords - erythrocyte; diffusion; spectrophotometer.

\section{INTRODUCTION}

The change in blood composition due to the presence of cancer cells will affect the erythrocyte cellular interaction. The interaction pattern of erythrocytes of normal and cancer subjects will be used to detect the cancer presence. This study is a part of a broader research on the early detection of the cancer malignancy. The objective of this research is to assess the application of Coulomb's law in complex systems from erythrocyte interactions in EDTA-Blood.

Erythrocytes in the blood are dispersed in the blood plasma, of which there are ions in the plasma. The interaction of ion with ion, ion with erythrocytes, ion with molecules seem like a mutual attraction and repulsion which causes coulomb force. The magnitude of the electrostatic force between the two charges is proportional to the product of the two charge magnitude and inversely proportional to the square of the distance between the two charges [1]. Erythrocytes are always moving in the plasma until it ends with the occurrence of erythrocyte sedimentation. Ions around the erythrocyte diffuse to form a dynamic balance.

The solid surface in contact with an aqueous solvent leads the composition of the ions in the solvent to have a non-zero total charge density near the interface [2]. The potential difference between the particle surface and the electroneutral region is known as Nernst (E) potential [3][4]. Around the colloid particle, the colloid potential on the diffused layer is lower than the surface potential. The potential between the sliding plane and the electro-neutral region is called zeta potential [3][4][5].

Zeta potential is an electrochemical aspect of the particle surface which provides information about the ability of dispersibility, aggregability, and adhesion. If the zeta potential values are around zero, the particles repulsive force will be weakened, and the particles will soon aggregate [6]. The magnitude of the zeta potential is inversely proportional to the ionic strength and influenced by different proteins. In addition to ionic strength, preferential adsorption of ions on the membrane also has an effect on the zeta potential [6][7]. Zeta potential as a basic parameter in controlling the stability or the repulsion degree of particles with close interaction (repulsive electrostatic intensity), the same electrical charge, the dispersed between the colloidal particles both for organic and inorganic materials [3][8]. Both the positive and negative high values of all the particles will lead to a stable dispersed colloidal [9]. The potential value below the threshold results in greater tensile strength than the repulsive 
force between adjacent particles. The magnitude of the zeta potential is affected by the surface charge and the double layer thickness [3][8].

Blood composition changes cause changes in erythrocyte movement and ion dynamics. The presence of proteins in the blood that is synthesized by cancer cells cause changes in the interactions between erythrocytes with ions and ions with ions. Ovarian cancer cells synthesize CA-125 protein as a biomarker into the blood [10] [11][12][13][14][15]. In addition to CA 125 , ovarian cancer also synthesizes Ca 19-9 protein [15]. The presence of this protein can decrease the zeta potential value. The charged protein will affect the interaction between ions and ion and also ion with erythrocytes. The total erythrocytes are quite a lot compared to the other main elements, so they are used as the main center of interaction in the blood [16]. The type and concentration of ions in solution affect the thickness of the double layer formed around the particles [17].

A dynamic equilibrium will be formed from the ion interaction, erythrocytes, and protein. Based on coulomb law, ions with the same charge will repel, and opposite ions will attract. As a result of this interaction, the positive ions are concentrated near the erythrocytes, and negative ions stay away from erythrocytes, thus forming an ionic double layer (Fig. 1) [18]. Negatively charged erythrocyte surface derived from sialic acid residues will attract the positive ions and repel with negative ions [19].

Diffusion is a molecule or particle displacement caused by the random motion of the molecule that mixing with other particles. The particles move from the higher to the lesser concentration region or to the region that occupied by other particles. The smaller the molecule size, the faster it moves $[20][21][22][23][24]$. The particles do not experience any change in the diffusion process. The diffusion is a spontaneous process [25].

The system's internal energy (U) includes all the kinetic and potential energy. Internal energy can be a translational kinetic energy of molecules, the molecular rotational and vibrational energy, the energy stored in chemical bonds and intermolecular attraction [1][20].

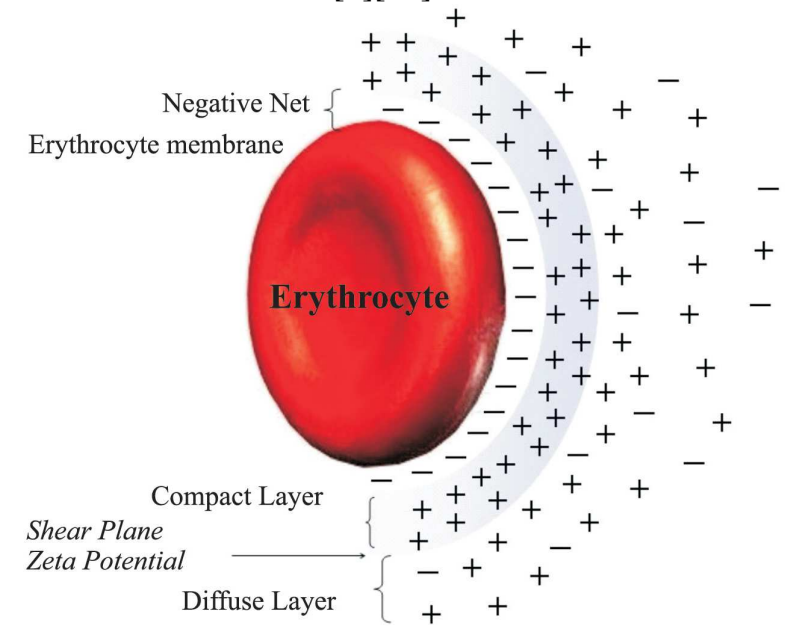

Fig. 1 Ion double layer around erythrocytes generating zeta potential between the two [20]

The electric force and the thermal motion maintain the balance of ions distribution in a solution. The equilibrium condition of the negative charged colloidal particle is excessively positive ions near the surface particle, and the remainder is distributed with decreasing amount away from the surface particle [4]. The attractive force between two ions with the opposite sign will stable the two ions. The presence of an electrostatic force makes two ions with the opposite sign $\left(\mathrm{q}_{1}\right.$ and $\left.\mathrm{q}_{2}\right)$ attracting each other, and the potential energy between them is showed by the equation (1), i.e.:

$$
U_{e}\left(r_{12}\right)=\frac{q_{1} q_{2}}{4 \pi \varepsilon_{0} r_{12}}
$$

with $U_{e}$ is the electric potential energy $(J), \varepsilon_{0}$ is the vacuum permittivity $\left(8,854 \times 10^{-12} \mathrm{C}^{2} \mathrm{~J}^{-1} \mathrm{~m}^{-1}\right), \mathrm{r}_{12}$ is the distance between the center of the charges $(m), \mathrm{q}_{1}$ and $\mathrm{q}_{2}$ are the ion charges [26].

The occurrence of inter-molecular forces is caused by the electrically charged particles of the constituent materials [22]. The electric force of the positive test charge $\left(q_{0}\right)$ residing in the electric field is $F=q_{0} E$. The potential energy of the interacting particles is calculated from the amount of the force required to move the particle at a certain distance. The test charge $q_{0}$ moves in an electric field $(E)$ as far as $d$ with the force and displacement are opposite then the work done by the electric force is $W=-q_{0} E d$ (in joule) and the potential energy of the charge changes, i.e.: $\Delta U=-W=q_{0} E d$ (in joule), whereas the potential change $(\Delta \mathrm{V})$ is $\frac{\Delta U}{q_{0}}=-\frac{W}{q_{0}}$ (in volt) [1] [27][24].

The potential energy of a pair of charged particles depends on the distance of the two charged particles. The magnitude of the potential energy at large distance between the two particles is zero. The lowest potential energy value shows the attraction force of the two particles balances the repulsive force. The repulsive force will be more dominant when the two particles are closer. The strong repulsion between centers of electron clouds causes this repulsive force when the particles get closer to each other [22].

Cells are an open and complex thermodynamic system. In open systems, exchanges of substances and heat with the environment occur [28][29][30][31]. Cells are open systems that maintain their structure in low entropy condition. They can exchange their entropy if they are far from equilibrium condition. The system is in steady state if the input and output are in equilibrium condition and do not show growth, but this does not match living organisms [30][32].

Based on the first law of Thermodynamics, energy is defined as the capacity to do work and to generate heat. Internal energy is the result of heat changes that enters the system and work done by the system. The direction of all processes that occur spontaneously is explained by the second law of Thermodynamics. The irreversible process moves towards increasing entropy [32]. The combination of these two laws in constant temperature $(T)$ and pressure $(p)$ condition describes the relationship of thermodynamic system state function changes, called Gibbs $(\Delta G)$, enthalpy $(\Delta H)$, and entropy $(\Delta S)$ free energies is showed by the equation (2) [32][33]. 


$$
\begin{aligned}
& d G=d H-T d S \\
& d U+p d V-T d S \leq 0 .
\end{aligned}
$$

The reaction equation under equilibrium condition causes the change in Gibbs free energy $(\Delta \mathrm{G})$ becomes 0 . In general, the equation of the reaction is given by

$$
a A+b B \rightleftharpoons c C+d D
$$

The change in Gibbs free energy when the reaction is to the right is showed by the equation (3) [34].

$$
\Delta G=\Delta G^{0}+R T \ln \frac{\left(a_{C}\right)^{c}\left(a_{D}\right)^{d}}{\left(a_{A}\right)^{a}\left(a_{B}\right)^{b}}
$$

with $R$ is the gas constant, $T$ is the absolute temperature, and as an example, $a_{\mathrm{C}}$ is the type $\mathrm{C}$ activity. The relation of Gibbs energy change with electric work on reversible condition is shown by the equation (4) [28].

$$
\Delta G=-w_{\text {elec }}=-Q \Delta E=-n F \Delta E(\text { reversible })
$$

with $w_{\text {elec }}$ is the electrical work (in joule), $n F$ is $n$ mol charge (in coulomb), $\Delta E$ is the reversible voltage (in volt). The combination of equation (3) with equation (4) is known as the Nernst equation which is shown by the equation (5).

$$
\begin{aligned}
& -n F \Delta E=-n F \Delta E^{0}+R T \ln \frac{\left(a_{C}\right)^{c}\left(a_{D}\right)^{d}}{\left(a_{A}\right)^{a}\left(a_{B}\right)^{b}} \\
& \Delta E=\Delta E^{0}-\frac{R T}{n F} \ln \frac{\left(a_{C}\right)^{c}\left(a_{D}\right)^{d}}{\left(a_{A}\right)^{a}\left(a_{B}\right)^{b}}
\end{aligned}
$$

\section{MATERIAL AND METHOD}

\section{A. Material}

The research sample used was blood (EDTA-blood). The blood material was taken from the vein of the forearm as much as $6 \mathrm{ml}$ by experts. The blood used is derived from normal subjects as many as 35 humans and ovarian cancer subjects as many as 34 humans. The normal subjects were people from the general public who do not have a history of cancer, not experiencing serious infections that are otherwise healthy by general practitioners. Ovarian cancer subjects were obtained from patients with ovarian cancer at Sardjito General Hospital Yogyakarta, aged 17-60 years, and did not suffer from any other cancer or inflammation expressed by a specialist physician based on PA examination and other supporting devices. The research was conducted in biochemistry laboratory of Medicine Faculty of Gadjah Mada University. Blood is inserted into an EDTA vacutainer so that the blood does not clot. Sampling for the study was approved by the Medical and Health Research Ethics Committee (MHREC) Faculty of Medicine Gadjah Mada University. Each study subject has approved the informed consent.

\section{B. Method}

The EDTA-blood cells interaction was observed using a spectrophotometer. Changes in the interaction of the EDTAblood cells were observed on the top of the EDTA-blood in the cuvette. The blood sample used was $550 \mu$ l. The wavelength used is $560 \mathrm{~nm}$. The time interval from the blood sample was taken until the examination is carried out is up to a maximum of 2 hours, the examination was carried out at a temperature of $24{ }^{\circ} \mathrm{C}$. The analog data from the sample absorbance is converted to digital data for data analysis purposes. Absorbance value data per unit time is recorded using a computer.

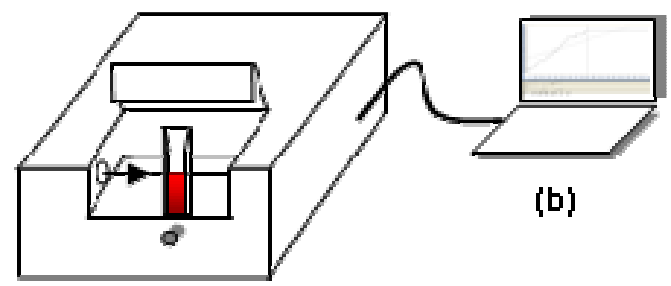

(a)

Fig. 2 The schematic of the apparatus, (a) a spectrophotometer and (b) a computer

The value of the absorbance pattern from the groups of research subjects was analyzed using deterministic and stochastic approaches. The parameter values of the normal and the ovarian cancer groups of subjects are tested using Ttest for normally distributed data or Mann-Whitney test for data which are not normally distributed to determine whether there was a difference of the parameters of the two groups. Both groups had significant differences in parameter values if the $p$-value $<0.05$ as the significant level. The absorbance pattern was analyzed using curve fitting against quadratic function called a deterministic model. The deterministic approach is used to simply analyze from definite variables in special conditions [35]. The complexity of the erythrocyte aggregation process was analyzed using a stochastic approach [35] [36] [37].

\section{RESULTS AND DISCUSSION}

\section{A. Pattern of Erythrocyte Interaction Absorbance}

Subjects of the study were 69 subjects; 35 normal subjects and 34 ovarian cancer subjects. The graphs of erythrocyte absorbance in blood-EDTA per time unit in the normal and the ovarian cancer subjects were grouped based on the similarity of the graphics. Representations of each group are depicted in Fig. 3. Based on the graph, it is difficult to directly distinguish the normal from the ovarian cancer groups using the erythrocyte absorbance patterns in the EDTA-blood. The absorbance pattern was analyzed using curve fitting against a quadratic function called the deterministic approach is shown in Fig. 4. The result of curve fitting against quadratic function produces values of parameter-1 (d3) showing curve concavity, parameter-2 (d2) showing the approximate peak and parameter-3 (d1) showing the intersection between the $y$-axis and the quadratic equation of $y=d 3 x^{2}+d 2 x+d 1$. 


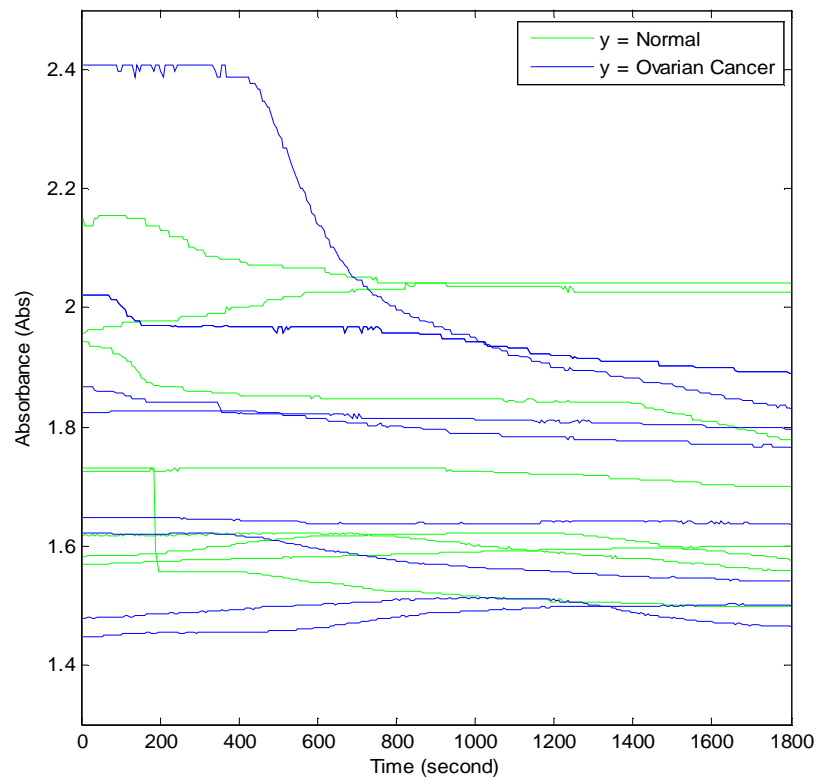

Fig. 3 Five-graph representations of erythrocyte absorbance per unit of time in each subject

A complex process occurs in the interaction of particles in the EDTA-blood during aggregation and sedimentation processes. These processes occur randomly and uncertain. The erythrocyte aggregation kinetic process is spontaneous and depends on its environment [38]. Some of the complexity in the aggregation process is affected by the conditions in the plasma, among others, due to intermolecular forces, electrostatic forces, and dynamics (kinetic energy) protein [39] [40]. In general, a stochastic approach using autocorrelation function is used to analyze complex processes. The result of the autocorrelation analysis was then fitted to the quadratic curve (Fig. 5). The results show that parameter-1 (s3) is curved inward; parameter-2 (s2) indicates the peak; and parameter-3 (s1) depicts the intersecting point of axis of the ordinate from quadratic equation of $y=s 3 x^{2}+s 2 x+s 1$. The graphs of the autocorrelation and curve fitting results are shown in Fig. 5.

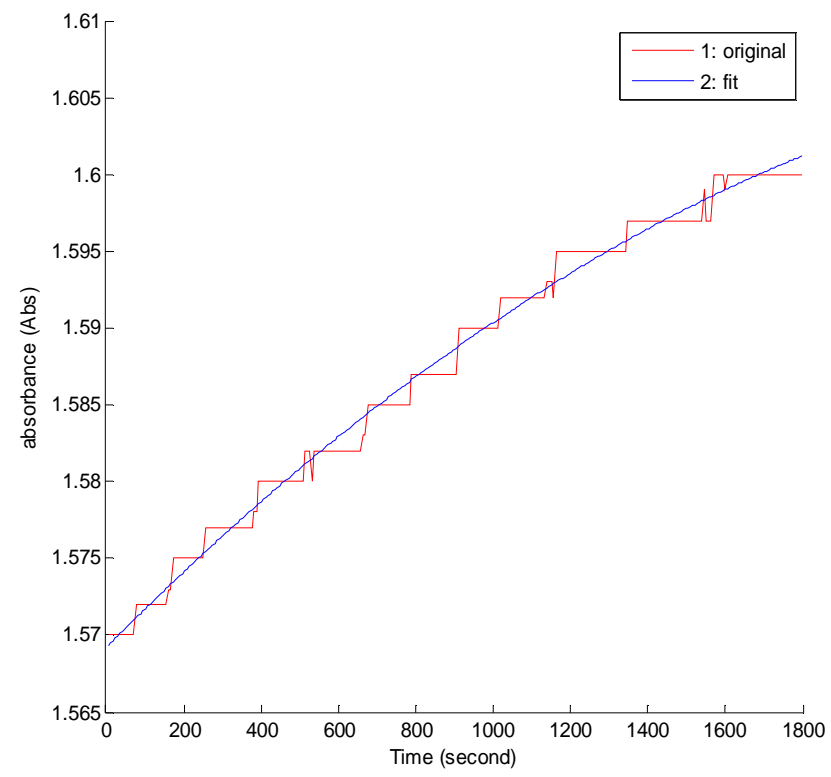

Fig. 4 Example of fitting curves for normal subject data
The data in parameters $\mathrm{d} 1$ and $\mathrm{s} 3$ were normally distributed which then t-test was used to see the difference among parameters in normal and cancer subjects. Data on parameters d2, d3, s1, and s2 were not normally distributed so that Mann-Whitney test was applied to measure the difference.

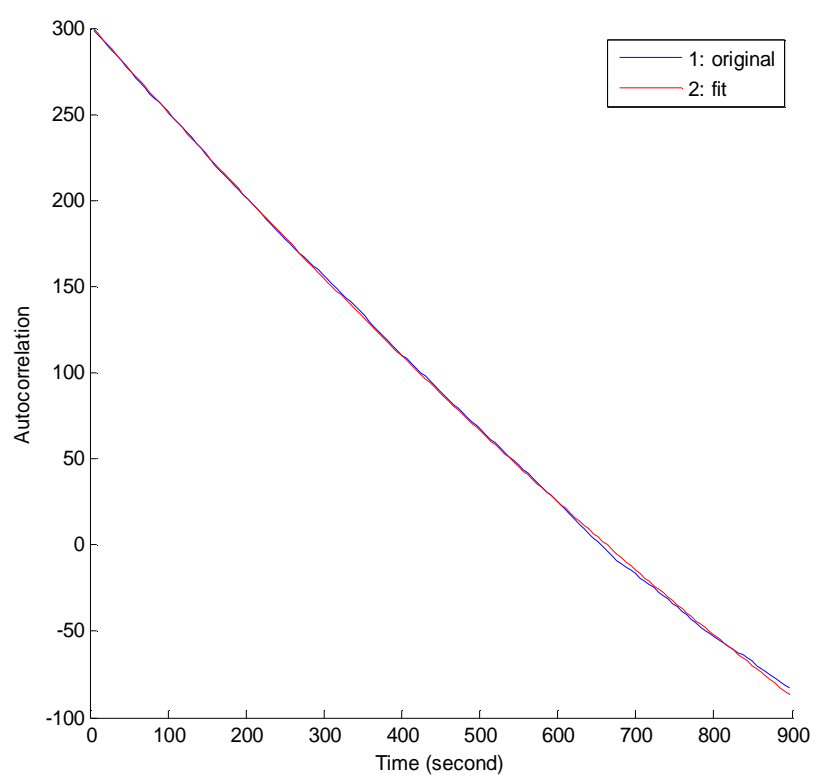

Fig. 5 Autocorrelation and quadratic fitting curves for normal-subject data

TABLE I.

THE RESULT OF MEAN AND DEVIATION IN NORMALLY-DISTRIBUTED PARAMETERS FOR NORMAL AND CANCER SUBJECTS.

\begin{tabular}{lccc}
\hline \multicolumn{1}{c}{ Subject } & \multicolumn{3}{c}{ Parameters } \\
\cline { 2 - 4 } & $\overline{d 1}(S D)$ & $\overline{s 1}(S D)$ & $\overline{s 3}(S D)$ \\
\hline $\begin{array}{l}\text { Normal } \\
\text { subjects }\end{array}$ & $1.67(0.18)$ & & $2.47 \mathrm{E}-4$ \\
$\begin{array}{l}\text { Cancer } \\
\text { subjects }\end{array}$ & $1.70(0.25)$ & $3.18 \mathrm{E}+2$ & $(2.18 \mathrm{E}-4)$ \\
& & $(18.62)$ & \\
\hline
\end{tabular}

TABLE II.

THE RESULT OF MINIMUM AND THE MAXIMUM VALUE OF ODDLYDISTRIBUTED PARAMETERS IN NORMAL AND OVARIAN CANCER SUBJECTS.

\begin{tabular}{llllll}
\hline \multirow{2}{*}{ Subject } & \multicolumn{5}{c}{ (Min- max) value } \\
\cline { 2 - 6 } & \multicolumn{1}{c}{$\mathbf{d 2}$} & \multicolumn{1}{c}{$\mathbf{d 3}$} & \multicolumn{1}{c}{$\mathbf{~ s 1}$} & \multicolumn{1}{c}{$\mathbf{~} 2$} & \multicolumn{1}{c}{$\mathbf{~ 3 3}$} \\
\hline Normal & $4.30 \mathrm{E}-5$ & $-5.86 \mathrm{E}-8$ & 208.20 & $-0,98$ & \\
& - & - & - & - & \\
& $1.35 \mathrm{E}-4$ & $1.29 \mathrm{E}-07$ & 365,70 & -0.46 & \\
& & & & & \\
Ovarian & $-7.94 \mathrm{E}-4$ & $-9.69 \mathrm{E}-8$ & & $-7.35 \mathrm{E}-1$ & $-4.18 \mathrm{E}-5$ \\
cancer & - & - & & - & - \\
& $2.27 \mathrm{E}-7$ & $2.20 \mathrm{E}-4$ & & -0.44 & $1.06 \mathrm{E}-3$ \\
\hline
\end{tabular}

The parameters values $(\mathrm{d} 1, \mathrm{~d} 2, \mathrm{~d} 3, \mathrm{~s} 1, \mathrm{~s} 2, \mathrm{~s} 3)$ of each data group (normal and ovarian cancer subjects) were compared to determine whether there was a difference of the parameters of the two groups. The test analysis uses T-test for normally distributed data and Mann-Whitney for data that is not normally distributed. The result of the test difference of $\mathrm{d} 1, \mathrm{~d} 2, \mathrm{~d} 3, \mathrm{~s} 1, \mathrm{~s} 2$, and $\mathrm{s} 3$ between two successive groups of P-count 0.612, 0.058, 0.310, 0.036, 
0.782 , and 0.408 was obtained. The values of P-arithmetic compared to the significance level value of $\alpha=0.05$ resulted in all values of P-count $>0.05$ in $\mathrm{d} 1, \mathrm{~d} 2, \mathrm{~d} 3, \mathrm{~s} 2$, and $\mathrm{s} 3$ parameters. This means that there is no significant difference between two groups in each parameter. The resulted in Pcount in parameter $\mathrm{s} 1$ is $<0.05$ meaning that there is a significant difference in parameter s1 between normal and ovarian cancer subjects.

\section{B. Discussion}

Interactions between erythrocytes may occur under three conditions. The conditions are: the erythrocytes from the initial position will be closer to each other, the erythrocytes away, or the erythrocytes overlap. The adjacent erythrocytes will experience a repulsive force that includes the steric force due to glycocalyx, and the electrostatic resistance force of the negative charge on the erythrocyte surface. The erythrocyte aggregation depends on the initial position of the cell and the strength of the adhesive forces compared to other forces, such as the hydrodynamic force [39]. The ionspecific interactions that occur in the particle environment can lead to changes in particle stability [41]. The interaction of erythrocyte cells can be illustrated in the following Fig. 6 .

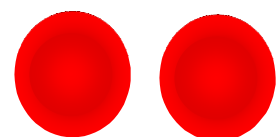

a. Initial condition
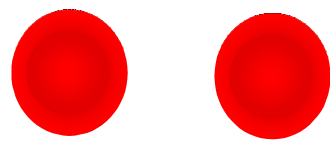

c. Away to each other

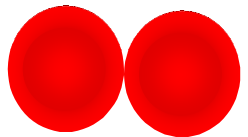

b. Closer to each other

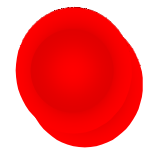

d. Overlapping
Fig. 6 Position of red blood cell interactions

Changes in position due to cellular interactions of erythrocytes may cause changes in the erythrocyte absorbance from the initial condition. The surface area of erythrocytes affects the number of light wavelengths being absorbed. The erythrocyte position perpendicular to the incoming light will maximally absorb the rays, while the erythrocyte with a certain angle with the light will reduce the amount of light absorbed. Erythrocyte positions which are overlapping each other will reduce the area of absorption. An aggregate of erythrocytes forms two or threedimensional structures when they are in a solution containing plasma protein [42].

The spectral line pattern shows the pattern of erythrocyte position change due to interactions between the erythrocytes (Fig. 7). The ab line increases as time changes indicating an increase in the absorption value. This condition is likely to show the erythrocytes are approaching each other. The bc line decreases with time indicating a decrease in the absorption value. This condition is likely to show erythrocytes are moving away from each other or in an overlapping situation. The horizontal cd line shows a constant absorbance value. This condition may indicate erythrocytes are at rest. The difference in slope between $a b$ and ef line shows the rate of change of position between different erythrocytes. The tendency of the absorbance pattern from a to $\mathrm{g}$ is decreasing. This condition indicates that erythrocytes undergo aggregation and moreover may have settled.

The aggregation process occurs when the erythrocytes approach each other and eventually converge. Aggregation is influenced by plasma percentage with macromolecular variation. Erythrocytes form rouleaux after aggregation [43]. After reaching a certain mass that is the downward force is greater than the upward force, the erythrocytes will experience sedimentation. This process will be repeated again for erythrocytes that have not yet aggregated. This repetitive process will be recorded on the absorbance data.

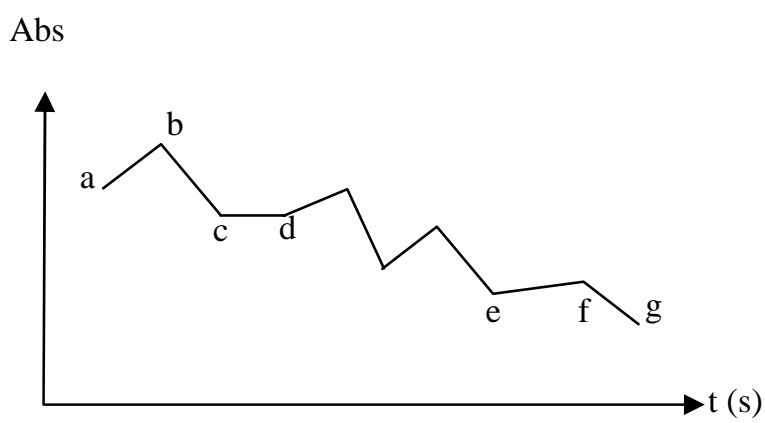

Fig. 7 Possible erythrocyte interaction patterns.

The blood plasma includes erythrocytes, ions, and proteins as [44][45][46][47]. Erythrocytes interact with ions, ions interact with ions, and ions interact with proteins in the blood plasma. The concentration and counter-ion type have an effect on the compression of the diffuse layer and the adsorption in the altered stern layer. This condition can be observed through the Zeta potential change [24]. The electrical double layer will be compressed with increasing ionic strength. In addition to ionic strength, preferential adsorption of membrane ions also affects the Zeta potential [7]. The equilibrium interaction occurs when particles are in equilibrium with the dispersing medium. These interactions include dispersion Van der Walls forces, electrostatic forces of the overlapped double layer, and various steric interactions [48]. Erythrocytes have negative charges on their surfaces derived from sialic acid residues. After forming an adjacent ionic double layer (E) in the surrounding, erythrocytes will form an equilibrium with the ion $(\mathrm{M})$ in the plasma. In the equilibrium reaction, $\mathrm{E}$ will bind with the ion to form EM, but EM will release $\mathrm{M}$ to $\mathrm{E}$. Along with this equilibrium reaction, in the plasma there is also an equilibrium reaction between proteins $\mathrm{P}$ and $\mathrm{M}$. $\mathrm{P}$ bind to $\mathrm{M}$ to form $\mathrm{PM}$, but $\mathrm{PM}$ will release $\mathrm{M}$ forming $\mathrm{P}$. Both of these equilibrium reactions occur at the same time as illustrated in Fig. 8.

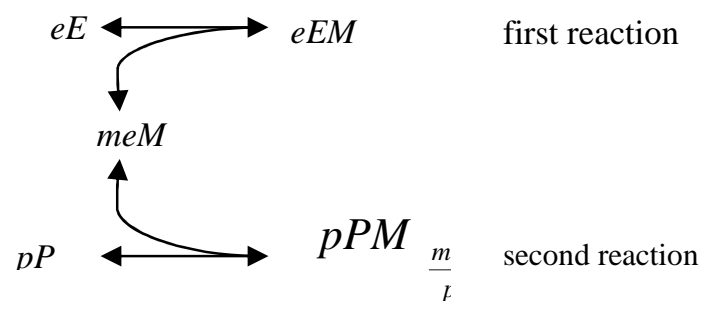

Fig. 8 The equilibrium reaction between $\mathrm{E}$ and $\mathrm{M}$, and $\mathrm{M}$ with $\mathrm{P}$. 
The equilibrium reaction is a reversible reaction having a constant equilibrium constant $(k)$ [18]. In general, the equilibrium equation can be shown in the following equation of mass-action law [18][20][26].

$$
\begin{gathered}
\mathrm{aA}+\mathrm{bB} \quad \mathrm{gG}+\mathrm{hH} \\
\frac{[G]^{g}[H]^{h}}{[A]^{a}[B]^{b}}=\frac{k_{1}}{k_{2}}=K_{C},
\end{gathered}
$$

with $k_{1}, k_{2}$ are reaction rates to the right and left; respectively, $K_{\mathrm{C}}$ is the equilibrium constant which is the ratio of $k_{1}$ and $k_{2}$. When equilibrium reaction happens, the value of Gibbs energy change is zero. The change of $G^{0}$ value occurring at equilibrium on $\mathrm{E}$ and $\mathrm{M}$ reactions are

$$
\begin{aligned}
\Delta G_{1}^{0} & =-R T \ln \frac{\left[E M_{m}\right]^{e}}{[E]^{e}[M]^{m_{2}}} \\
e^{\frac{-\Delta G_{1}^{0}}{R T}} & =\frac{\left[E M_{m}\right]^{e}}{[E]^{e}[M]^{m_{2}}},
\end{aligned}
$$

With $m e=m_{2}$. The change in the value of $\mathrm{G}^{0}$ occurring on equilibrium at the second reaction is

$$
\begin{aligned}
\Delta G_{2}^{0} & =-R T \ln \frac{[P]^{p}[M]^{m_{2}}}{\left[P M_{m_{3}}\right]^{p}} \\
e^{\frac{-\Delta G_{2}^{0}}{R T}} & =\frac{[p]^{p}[m]^{m_{2}}}{\left[P M_{m_{3}}\right]^{p}},
\end{aligned}
$$

with $\frac{m e}{p}=m_{3}$. Based on equations (6) and (7), Equation (8) and (9) are generated.

$$
\begin{aligned}
& {[M]^{m_{2}}=e^{\frac{\Delta G_{1}^{0}}{R T}}[E M m]^{e}[E]^{-e}} \\
& {[M]^{m_{2}}=e^{\frac{-\Delta G_{2}^{0}}{R T}}\left[P M_{m_{3}}\right]^{p}[P]^{-p}}
\end{aligned}
$$

Both equations (8) and (9) may be combined to become

$$
\begin{gathered}
e^{-\Delta G_{2}^{0}\left[\frac{P M m_{3}}{P}\right]^{p}}=\left[\frac{E M m}{E}\right]^{-e} \\
\frac{\left.e^{-\left(\frac{\Delta G_{1}^{0}}{R T}\right.} \frac{\Delta G_{1}^{0}}{R T}\right)}{\left(\frac{P M m_{3}}{P}\right)^{p}}=\left(\frac{E M m_{2}}{E}\right)^{-e} .
\end{gathered}
$$

Inserting the ratios $\mathrm{P} \quad(\mathrm{rP})=\left(\frac{P M m_{3}}{P}\right)$ and $\mathrm{E}$ $(\mathrm{rE})=\left(\frac{E M m_{2}}{E}\right)$ the above equation becomes

$$
\begin{aligned}
& \ln e^{-\Delta \Delta \frac{G^{0}}{R T}}-p \ln r P=-e \ln r E \\
& \frac{-\Delta \Delta G^{0^{1}}-p \ln r P}{-e}=\ln r E \\
& r E=e^{\frac{\Delta \Delta G^{0^{1}}+p \ln r P}{e}}
\end{aligned}
$$

The interaction pattern of erythrocytes in the EDTAblood of normal and ovarian cancer subjects was compared based on the values of each parameter $\mathrm{d} 1, \mathrm{~d} 2$, $\mathrm{d} 3, \mathrm{~s} 1, \mathrm{~s} 2$, and s3. The analysis result shows that there is no difference in both groups from each parameter. The values of these parameters cannot distinguish between normal and ovarian cancer subjects. The complexity of EDTA-blood compositions of normal and cancer subjects result in an erythrocyte interaction pattern. The randomly distributed erythrocytes in the blood plasma interact toward an ordered state. This condition causes the entropy of the system to decrease [30]. The living cells can perform a series of chemical reactions and actively modify their behavior when there is a change in their environment [29]. Changes in plasma from ovarian cancer patients include increasing lysophosphatidic acid (LPA) and human epididymis protein 4 (HE4), which can be used as an ovarian cancer biomarker. The amount of LPA is greater than that of CA-125 in the diagnosis of ovarian cancer [47][49][50].

Erythrocyte interactions in EDTA-blood have not been able to be explained microscopically. The macroscopic approach is conducted by measuring macroscopic parameters such as heat, temperature, displacement, force, and work. The relationship between parameters is made to form a mathematical function, and the classical thermodynamic laws barely understand the microscopic conditions of the material [51]. The cell is a complex system, hence to understand it is by means of its mechanisms into subdivisions and describing this sub-section in detail [51].

\section{CONCLUSIONS}

The erythrocyte interaction in EDTA-blood is a complex system. The application of Coulomb's law from erythrocyte absorbance patterns cannot distinguish between erythrocyte interaction patterns in normal and ovarian cancer subjects. The parameters of $\mathrm{d} 1, \mathrm{~d} 2, \mathrm{~d} 3, \mathrm{~s} 1, \mathrm{~s} 2$, and $\mathrm{s} 3$ of the two groups were tested based on the average difference. The calculation result obtains $\mathrm{P}$ values of $0.612,0.058,0.310$, $0.036,0.782$, and 0.408 . There is no significant difference in 
both groups in parameters $\mathrm{d} 1, \mathrm{~d} 2, \mathrm{~d} 3, \mathrm{~s} 2$, and $\mathrm{s} 3$. On the other hand, there is a significant difference between normal and ovarian cancer groups for parameter $\mathrm{s} 1$ indicated in the P-value of $<0.05$. Complex EDTA-blood composition affects the interaction of erythrocyte as living cells.

\section{ACKNOWLEDGMENT}

The authors would like to thank the Director of Human Resources and Education of Sardjito General Hospital who gave the research permission to obtain blood samples, volunteers who have donated blood, research funding of DAMAS Medical Faculty, Gadjah Mada University, head of Biochemistry laboratory of Medical Faculty, Gadjah Mada University who has given the permission to use laboratory equipment, Biochemistry laboratory assistant of Medical Faculty, Gadjah Mada University who has provided equipment services.

\section{REFERENCES}

[1] J.S. Walker, Physics, 4th. ed., San Fransisco: Pearson AddisonWesley, 2010.

[2] A. Sze, D. Erickson, L. Ren, and D. Li, "Zeta-potential measurement using the Smoluchowski equation and the slope of the current-time relationship in electroosmotic flow", Journal of Colloid and Interface Science, Vol. 261, pp. 402-410, May 2003.

[3] L. Prokai, V. Nguyen, B.R. Jasti, T.K. Ghosh, principles and applications of surface phenomena, edited by T.K. Ghosh, B.R. Jasti, Theory and Practice of Contemporary Pharmaceutics, Baca Raton: CRC Press, 2005.

[4] M.T.H. Nutan, I.K. Reddy, Edited by: A.K. Kulshreshtha, O. N. Singh, G. M. Wall, Pharmaceutical Suspensions from Formulation Development to Manufacturing, New York: Springer Science+Business Media. 2010.

[5] I. Larson, P. Attard, "Surface Charge of Silver Iodide and Several Metal Oxides. Are All Surfaces Nernstian?", Journal of colloid and interface science, V. 227, pp.152-163, March. 2000.

[6] E. H. Hayakawa, S. Kobayashi, H. Matsuoka, "Physicochemical Aspect of the Plasmodium chabaudi-Infected Erythrocyte", BioMed Reseach International, Volume 2015, pp. 1-8, Jul. 2015.

[7] S. Salgin, U. Salgin, N. Soyer, "Streaming Potential Measurements of polyethersulfone Ultrafiltration Membrane to Determine salt effect on membrane zeta potential". International Journal of Electrochemical Science, Vol.8, pp. 4073-4084, March. 2013.

[8] V. Uskoković, R. Odsinada, S. Djordjevic, S. Habelits, Dynamic light scattering and zeta potential of Colloidal mixture of amelogenin and hydroxyapatite in Calcium and Phosphate rich ionic milieus. Arch Oral Biol., Vol. 56(6), pp. 521-532, June 2011.

[9] M. Sabbah, M. Esposito, P.D. Pierro, C.V.L. Giosafatto, L. Mariniello, and R. Porta, "Insight into Zeta Potential Measurements in Biopolymer Film Preparation". Journal Biotechnol Biomater,Vol. 6, pp. 6:2, 2016.

[10] F. Morales-Vásquez, H. N. López-Basave, C. Méndez, D.G. Rincón, C. C. Blanco, W. R. Muñoz, J. L. Aguilar-Ponce, and J. G. De La Garza-Salazar, "In Search of the Ideal Tumor marker for Epithelial Ovarian Cancer: serum Antigen CA-125 versus HE4 and others; current status and Clinical Utility", Journal of Cancerology, vol. 1, pp. 9-15, Sep. 2014

[11] G. Sölétormos, M. J. Duffy, S. A. A. Hasan, R.H.M Verheijen, B. Tholander, R.C. Bast, K.N. Gaarenstroom, C.M.Strugeon, J.M. Bonfer, P. H. Petersen, H Troonen. G. CarloTorre, J.K. Kulpa, M.K. Tuxen, and R. Molina. 2016. "Clinical Use of Cancer Biomarker in Epithelial Ovarian Cancer", International Journal of gynecological Cancer. Vol. 26, pp. 43-51, Jan. 2016.

[12] N. Lahlou, J.L. Brun, "Ovarian Tumor Markers of Presumed Benign Ovarian Tumors", J Gynecol Obstet Biol reprod (Paris). Vol. 42(8), pp. 752-9, Dec. 2013.

[13] M.C. Savithri, U.M. Abraham, "Massa lesions of ovary-Tumor marker can be misleading". Asian Journal of Medical Science, vol.6, pp. 26-29, May-Jun. 2015.

[14] M.K. Tuxen, G. Sölétormos, P. Dombernowsky, Serum Tumor marker CA 125 in Monitoring of Ovarian cancer during first-line
Chemotherapy, British Journal of Cancer, Vol. 84(10), pp.13011307, 2001.

[15] H.S. Al-Hadithi, A.R. Al-derzi,"Ca19-19 tumor marker in comparison with CA125 in patients with gynecological diseases". Journal of Dental and Medical Sciences. Vol.13. pp. 01-04. Feb. 2014.

[16] S. Rathore, B. Ali, "Effect of laser radiation on electrical conductivity of human". International Journal of Science, environment and technology, Vol. 3, pp. 286-290, Feb. 2014.

[17] A.K. Kulshreshtha, O.N. Singh, G.M. Wall, Pharmaceutical Suspensions from Formulation Development to Manufacturing, New York, United States of America: Springer Science+Business Media, 2010.

[18] H. P. Fernandes, C. L. Cesar, M. de L. Barjas-Castro,"Electrical Properties Of the red blood cell membrane and immunohematological investigation". Rev Bras hematol hemoter. Vol. 33(4), pp. 297-301. 2011

[19] T. L. Fabry, (1987). "Mechanism of Erythrocyte Aggregation and Sedimentation". Blood, Vol 70, No 5, pp. 1572-1576, Nov. 1987.

[20] R.H. Petrucci, F.G. Herring, J.D. Madura, C. Bissonnette, General chemistry principles and modern Application tenth edition, Toronto: Pearson Canada, Inc., 2011.

[21] R. M. J. Cotterill, Biophysics An Introduction, England: Jhon Wiley \& Sons Ltd, 2002

[22] D.W. Oxtoby, H.P. Gillis, A. Campion, H.H. Helal, K.P. Gaither Principles of Modern chemistry, Belmont, United States of America: Thomson Brooks/Cole, 2008.

[23] J.L. Kee, B.J. Paulanka, C. Polek, Handbook of Fluid, electrolyte, and acid-base imbalances third Edition, Clifton Park: Delmar Cengage Learning, 2010.

[24] J. Goodwin, Colloids and Interfaces with Surfactants and Polymer Second Edition, West Sussex: John Wiley and Sons, Ltd, 2009.

[25] P. Monk, physical Chemistry understanding our chemical World, West Sussex: John Wiley \& Sons, Ltd, 2004.

[26] D.W. Oxtoby, H.P. Gillis, A. Campion, H.H. Helal, K.P. Gaither, Principles Of Modern Chemistry seventh Edition, Belmont, United States of America: Brooks/Cole Cengage Learning, 2012.

[27] D. J. Griffiths, Introduction to Electrodynamics Third Edition, New Jersey: Prentice-Hall, 1999.

[28] U. Lucia, A. Ponzetto, T. S. Deisboeck. (2014). A thermo-physical analysis of the proton pump vacuolar-ATPase: the constructal approach. [online]. Available: http://www.nature.com/articles/srep06763

[29] U. Lucia, G. Grazzini, B. Montrucchio, G. Grisolia, R. Borchiellini, G. Gervino, C. Castagnoli, A. Ponzetto, F. Silvagno. (2015). Constructal thermodynamics combined with infrared experiments to evaluate temperature differences in cells. [online]. Available: http://www.nature.com/articles/srep11587.

[30] M. Popović, Entropy change of open thermodynamic systems in selforganising process. Thermal Science. Vol. 18, pp. 1425-1432, 2014.

[31] Y. Demirel, S. I. Sandler, Thermodynamics and bioenergetics, Biophysical Chemistry, Vol. 97, pp.87-111, 2002.

[32] V. Saks, C. Monge, T. Anmann, P. P.Dzeja. Molecular System Bioenergetics Energy for Life, edited by V. Saks, Weinheim, Germany: Wiley-VCH Verlag GmbH \& Co.KGaA, 2007.

[33] P. Atkins, J. de Paula, Physical Chemistry, 9th Ed., Great Britain: England: Oxford University Press, 2010:121

[34] P. H. Rierger, Electrochemistry second edition, New York: Chapman \& Hall, Inc., 1994.

[35] D.S. Lemons, An Introduction to Stochastic Processes in Physics, Maryland, United States of America: The Johns Hopkins University Press, 2002.

[36] M. Lefebvre, Applied Stochastic Processes, New York: Springer Science+business Media LLC, 2007.

[37] G.S. Ladde, M. Sambandham, Stochastic Versus Deterministic Systems of Differential Equations, New York Marcel Dekker, Inc, 2004.

[38] K. Lee, M. Kinnunen, M.D. Khokhlova, E.V.Lyubin, A. V. Priezzhev, I. Meglinski, A. A. Fedyanin, "Optical Tweezers study of Red Blood Cell Aggregation and Disaggregation in Plasma and Protein solution". Journal of Biomedical Optics. Vol. 21(3), pp. 035001-1 - 035001-10, March. 2016.

[39] Y. Liu, L. Zhang, X. Wang, W. K Liu, Coupling of Navier-Stokes Equation with Protein Molecular Dynamic and It Application to Hemodynamics.International journal for numerical methods in fluids. Vol. 46, pp.1237-1252. Oct. 2004 
[40] H.P. Fernandes, A. Fontes, A. Thomaz, V. Castro, C.L. Cesar, M.L., Barjas-castro, Measuring red blood cell aggregation force using double optical tweezers, Scand J clin Lab Invest. V. 73(3), pp.262-4. Apr. 2013.

[41] C. Pfeiffer, C. Rehbock, D. Hühn, C. Carillo-Carioni, D. j. de Aberrasturi, V. Merk, S. Barcikowski and W.J. Parak, "Interaction of colloidal nanoparticles with their local environment: the (ionic) nano environment around nanoparticles is different from bulk and determines the physicochemical properties of the nanoparticles", Journal of the royal society Interface, vol. 11: 20130931, pp.1-13, Apr. 2014.

[42] O.K Baskurt, H.J. Meiselman, "Erythrocyte aggregation: basic aspects and clinical importance", Clinical Hemorheology and Microcirculation, V. 53, pp. 23-37, 2013.

[43] H.J. Meiselman, B. Neu, M.W. Rampling, O.K. Baskurt, "RBC aggregation: Laboratory data and model", Indian Journal of Experiment Biology. Vol. 45, pp.9-7. Jan. 2007.

[44] R. K. Murray, P. A. Mayes, V.W. Rodwell, Harper's Illustrated Biochemistry, Twenty-sixth Edition, New York: McGraw-Hill Companies, 2003.

[45] G. Pocock, C. D. Richards, Human PhysiologyThe Basis of Medicine 3hd ed., London: Oxford University Press, 2006.
[46] B.J.D. Rein, S. Gupta, "Potential Markers for Detection and Monitoring of Ovarian Cancer", Journal of Oncology, Vol. 2011, pp. 1-17, Feb. 2011.

[47] L. Fan, M. Yin, C. Ke, T. Ge, G. Zhang, W. Zhang, X. Zhou, G. Lou, $\mathrm{K}$. Li, " Use of Plasma Metabolomics to Identify Diagnostic Biomarkers for Early-stage Epithelia Ovarian Cancer", Journal of Cancer, V. 7, pp. 1265-1272, June. 2016.

[48] A.S. Dukhin, P.J. Goets, Characterization of Liquids, Nano- and Microparticulates, and Porous Bodies Using Ultrasound, 2nd ed. Oxford, United Kingdom : Elsevier B.V, 2010.

[49] Y. Li, W. Zhang, J. Zhang, C. Zheng, H. Zhu, H. Yu, L. Fan. Plasma levels of Lysophosphatidic acid in ovarian cancer versus controls: a meta-analysis, Lipids in health and disease, Vol. 14:72, pp. 2-9, July. 2015.

[50] Y. Zhang, L. Cao, Z. Fu, Y. Wang, G. Wang, T. Gu, Clinical Significance of Plasma Lysophosphatidic acid levels in the Differential Diagnosis of Ovarian Cancer. Vol. 11, pp. 375- 380. Apr- June. 2015.

[51] M. Gonzalez-Gaitan, A. Roux, when cell biology meets theory, Journal Cell Biology. Vol. 210. Pp. 1041-1045, Sep. 2015. 